Florida International University FIU Digital Commons

4-6-2000

\title{
Clinician perceptions of factors that enhance patient compliance in physical therapy
}

Victoria R. Benea

Florida International University

DOI: $10.25148 /$ etd.FI14050498

Follow this and additional works at: https://digitalcommons.fiu.edu/etd

Part of the Physical Therapy Commons

\section{Recommended Citation}

Benea, Victoria R., "Clinician perceptions of factors that enhance patient compliance in physical therapy" (2000). FIU Electronic Theses and Dissertations. 1501.

https://digitalcommons.fiu.edu/etd/1501

This work is brought to you for free and open access by the University Graduate School at FIU Digital Commons. It has been accepted for inclusion in FIU Electronic Theses and Dissertations by an authorized administrator of FIU Digital Commons. For more information, please contact dcc@fiu.edu. 


\section{FLORIDA INTERNATIONAL UNIVERSITY}

Miami, Florida

CLINICIAN PERCEPTIONS OF FACTORS THAT ENHANCE PATIENT COMPLIANCE IN PHYSICAL THERAPY

A thesis submitted in partial fulfillment of the requirements for the degree of

MASTER OF SCIENCE

in

PHYSICAL THERAPY

by

Victoria R. Benea

2000 
To: Dean Ronald Berkman

College of Health Sciences

This thesis, written by Victoria R. Benea, and entitled Clinician Perceptions of Factors that Enhance Patient Compliance in Physical Therapy, having been approved in respect to style and intellectual content, is referred to you for judgment.

We have read this thesis and recommend that it be approved.
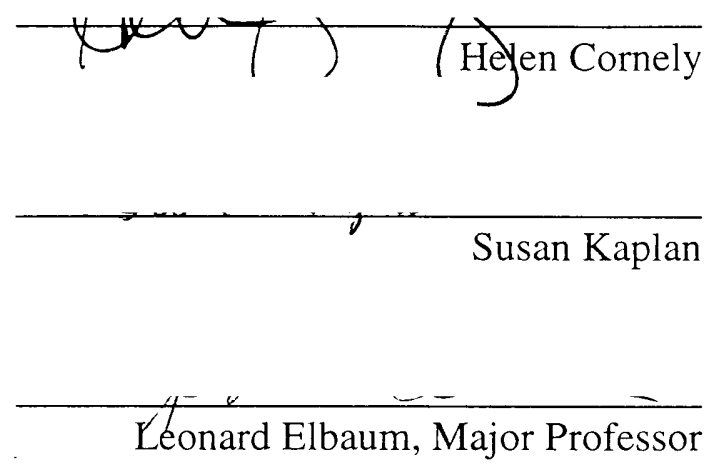

Date of Defense: April 6, 2000

The thesis of Victoria R. Benea is approved.

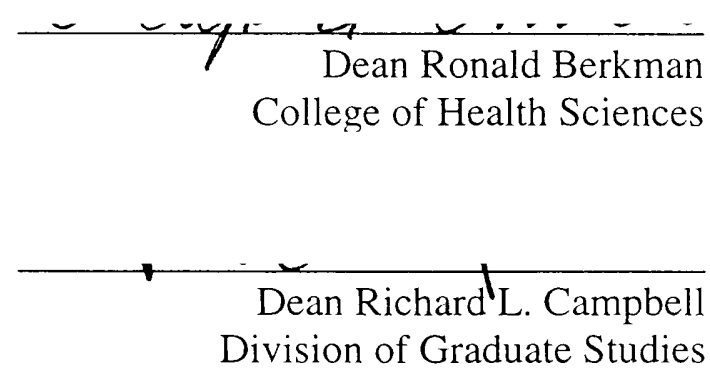

Florida International University, 2000 


\section{DEDICATION}

I dedicate this thesis to my husband Bruce, a man who possesses great patience; my sister Fred and family (Dave, John, and Brian); my father and stepmother, Bob and Linda; my mother and stepfather, Marguerite and Ralph; and my in laws, Laddie and Ida Mae.

I also want to thank my human friends, Eileen, Laura, Bob, John, Joan, Jeannie, and Susan. My four-legged friends demanded that I include them, Sinbad, BD, Maggie, Hunter, Louie, Billy, Natasha, Om, Zena, Oliver, Boomer, and Domino. Long may they run. If this dedication had a sound track, it would be Natalie Merchant singing, I want to thank you, thank you...

I also dedicate this in loving memory of Bobby, Tommy, and Ralph B. 


\section{ACKNOWLEDGMENTS}

I wish to thank all members of my committee for their time and patience, Dr. Leonard Elbaum, Dr. Susan Kaplan, and Helen Cornely. I want to give special thanks to Dr. Elbaum for his help with statistical analysis and his keen insights, on the thesis and life.

I also want to acknowledge the judicious use of the I-Ching. 


\title{
ABSTRACT OF THE THESIS
}

\section{CLINICIAN PERCEPTIONS OF FACTORS THAT ENHANCE PATIENT}

\section{COMPLIANCE IN PHYSICAL THERAPY}

by

\author{
Victoria R. Benea
}

Florida International University, 2000

Miami, Florida

Professor Leonard Elbaum, Major Professor

The purpose of this study was to determine physical therapists utilization of methods to increase compliance with home exercise programs, and to determine their perceptions of barriers patients have to completing exercise programs. The secondary purpose of this study was to describe the association, if any, between therapists' age, participation in exercise and/or lifestyle changes and the utilization of methods to increase exercise compliance.

A sample of 73 physical therapists attending the American Physical Therapy Association Combined Sections Meeting were surveyed for this study.

This study found that barriers listed by patients were similar to those found in the literature. This study also found that a significant association, $\mathrm{p}=.015$, existed between therapists engaging in behavioral changes and use of lifestyle activities. 


\section{TABLE OF CONTENTS}

CHAPTER

I. INTRODUCTION 1

Purpose of the study 2

Statement of the problem $\quad 2$

Research questions $\quad 3$

Assumptions 4

II. LITERATURE REVIEW 5

Benefits of exercise 5

Self-efficacy as theoretical framework $\quad 7$

Effects of self-efficacy on skill and exercise performance 10

Models for behavioral modification $\quad 12$

Use of positive feedback $\quad 15$

Use of lifestyle activities $\quad 16$

$\begin{array}{ll}\text { Gender related barriers to exercise } & 18\end{array}$

Socioeconomic barriers to exercise 19

Age related barriers to exercise 20

Additional barriers to exercise 21

III. METHODOLOGY 24

Objectives and research questions 24

Subjects 24

Setting 25

Instrument design $\quad 25$

Procedure 26

Data analysis $\quad 26$

IV. RESULTS 27

Characteristics of the survey respondents 27

$\begin{array}{ll}\text { Pearson Chi-Square values } & 37\end{array}$

V. DISCUSSION 39

Home exercise programs $\quad 39$

Lifestyle activities $\quad 39$

Patient reasons for noncompliance $\quad 40$ 
Increasing positive feedback to increase patient compliance

Therapists suggesting distraction techniques

Therapists engaging in weekly exercise

43

Therapists engaging in lifestyle changes

Relationship between therapists behavior

and exercise prescription

Responses to advice to physical therapy students to achieve patient compliance

Suggestions for further research

Summary 


\section{LIST OF TABLES}

TABLE

PAGE

1. YEARS OF EXPERIENCE AS A PHYSICAL THERAPIST

2. AGE OF THERAPIST

3. PERCENTAGE OF PATIENTS RECEIVING HOME EXERCISE PROGRAMS

4. PERCENTAGE OF PATIENTS RECEIVNG LIFESTYLE ACTIVITY SUGGESTIONS

5. FIRST RANKED REASONS PATIENTS STATE FOR EXERCISE NONCOMPLIANCE

6. INCREASING POSITIVE FEEDBACK INCREASES

PATIENT COMPLIANCE

7. PATIENTS RECEIVING FEEDBACK ON EXERCISE EFFECTIVENESS

8. THERAPISTS USING DISTRACTION TECHNIQUE 34

9. THERAPISTS ENGAGED IN WEEKLY EXERCISE ROUTINE 35

10. THERAPISTS MAKING LIFESTYLE CHANGE FOR HEALTH IMPROVEMENT

11. ADVICE TO INCREASE PATIENT COMPLIANCE 


\section{CHAPTER 1}

\section{$\underline{\text { Introduction }}$}

Optimizing patient compliance with prescribed home exercise routines should always be a goal for physical therapists. Compliance has been defined as the extent to which a person follows medical or health recommendations, such as taking medications or making lifestyle changes (Blackwell, 1992). Compliance with physical therapy recommendations for exercise programs has not been the focus of many investigations. A survey of physical therapists in the Netherlands revealed that therapists believe only $23 \%$ of their patients comply with exercise routines on a long-term basis (Sluijs and Kuijper, 1990).

Lack of patient compliance is well documented in studies citing failure to adhere to a prescribed medication regime (Straka et al., 1996, Friday, 1999). As previously stated, there are few studies on patient (Clopton, 1992; Sluijs et al., 1993; Jensen, 1994; Crook et al., 1998) compliance with exercise routines in physical therapy. The duty of a physical therapist is to guide the patient towards a more functional and independent lifestyle. A therapeutic exercise regimen is often employed as a means of increasing the patient's functional capacity in the practice of physical therapy. The issue of patient compliance with a therapeutic exercise regime therefore becomes one of great importance to the physical therapist, particularly if it is a primary means of delivering patient care. If the patient does not follow the proposed exercise guidelines, the efficacy of treatment decreases, leading to a potential cascade of problems. The patient may lose faith in the field of physical therapy, feeling that the treatment does not provide the results he or she 
had anticipated. This may lead to further non-compliance or disregard for following a proposed exercise regime.

Physical therapists have traditionally compiled therapeutic exercise routines based on anatomical and physiological considerations. Recent research has begun to focus on efforts to understand and increase patient compliance by examining the underlying cognitive factors associated with motivation for the lifestyle changes needed to begin an exercise routine. If the cognitive and perceptual structures underlying the mechanism to change can be understood, enhanced cooperation with exercise programs may be an achievable goal.

\section{Purpose of the study}

The purpose of this study was to determine physical therapists: (1) utilization of methods to increase compliance with home exercise programs, and (2) perceptions of barriers patients have to home exercise programs.

The secondary purpose of this study was to describe the association, if any, between therapists' age, participation in exercise and/or lifestyle changes and the utilization of methods of exercise prescription.

Statement of the problem

Patient compliance with a home exercise program is an important part of the treatment process. There are numerous studies on barriers patients perceive to complying with exercise recommendations prescribed by a physical therapist, physician, or nurse (Godin et al., 1991; Cousins, 1996; Johnson and Heller, 1998; Lieberman et al., 
1998). There are also numerous studies involving patient compliance with cardiac rehabilitation programs (Becker et al., 1980; Ice, 1985; Bock et al., 1997; Burke et al., 1997). Unfortunately, there are limited studies on patient compliance with home exercise programs in physical therapy (Sluijs and Kuijper, 1990, Jensen and Lorish, 1994, Crook et al., 1998).

The purpose of this study was to determine if methods used by physical therapists are similar to methods that have been shown to increase patient compliance with various exercise programs ( Ice, 1985; Jensen and Lorish, 1994; Bock et al., 1997; Burke et al., 1997; Crook et al., 1998) and to determine if the reasons patients routinely give for not complying with a home exercise program are similar to those reasons found by other studies (Dishman et al., 1985; Verhoef and Love, 1992; Dunlap and Barry, 1999; Dunn et al., 1999; Harnack et al., 1999; Neis et al, 1998 and 1999). Another purpose of this study is to describe the association, if any, between therapists' participation in exercise and/or lifestyle changes and their method of exercise prescription.

\section{$\underline{\text { Research Questions }}$}

This study was designed to answer several research questions. These questions include:

1. Do physical therapists routinely suggest lifestyle activities as part of an exercise program?

2. Do physical therapists utilize feedback to increase patient compliance with home exercise programs? 
3. Are the reasons patients give physical therapists for noncompliance with home exercise programs similar to those found in the literature?

4. Are there any associations between therapists' participation in exercise and/or lifestyle changes and their method of exercise prescription?

5. Are there any associations between therapists' age and their participation in weekly exercise?

\section{$\underline{\text { Assumptions }}$}

It is assumed that the information provided by the respondents to the questionnaire will be true and accurate to the best of their abilities. 


\section{CHAPTER 11}

\section{Review of the literature}

\section{Benefits of exercise}

A disregard for the benefits of exercise is not limited to the segment of the population receiving care from physical therapists. A study by Jones et al. (1998) on exercise practices of a sample of almost 30,000 people was extrapolated to reveal that only about one third of the population of adults in the United States meet the recommendations of the American College of Sports Medicine for moderate activity. Numerous studies collaborate this view of an increasing amount of healthy adults leading sedentary lifestyles. The levels of physical activity are decreasing despite the potential benefit of exercise. Exercise has been associated with reductions in risk factors for disease states such as heart disease, osteoporosis, and diabetes, and to contributing to an increased life expectancy (Erikssen et al., 1998, Wannamethee, 1998 American College of Sports Medicine, 1998b). Another benefit is improved postural stability, reducing the risk of falling and associated injuries, which can be debilitating to the elderly (American College of Sports Medicine, 1998b).

Patient compliance in cardiovascular rehabilitation programs is a growing concern. Cardiovascular disease is now the leading cause of mortality and morbidity in the United States (American Heart Association, 1995). Researchers in the 1960's found that exercise improved oxygen uptake, lowered myocardial oxygen demand, decreased blood pressure at a stated workload, and increased the exercise threshold for the onset of cardiac-related symptoms (Kavanaugh, 1974). Exercise also reduces coronary artery disease risk by raising the level of circulating high-density lipoproteins (Tran, 1983), 
increasing the sensitivity of insulin receptors, and reducing body fat (Wenger, 1997).

Despite the documented benefits of exercise, however, less than $20 \%$ of patients with coronary artery disease participate in cardiac rehabilitation, with a disproportionate number of older adults, women and minorities representing non-participants.

Wannamethee et al. (1998) studied the relationship between physical activity and incidence of major coronary heart disease in 4311 older men. They found that the benefits of exercise were restricted to light or moderate activity and did not apply to vigorous activity for a 3-year risk of major fatal and nonfatal coronary heart disease. Men who became inactive had the highest overall risk for fatal and non-fatal coronary heart disease. The study also found that physical activity initiated after a sedentary life also conferred the benefit of decreased risk.

A longitudinal study of by Erikssen et al. (1998) also found that even small improvements in physical activity are associated with a significantly lowered risk of death. The data collection for this study began in 1972 with the first survey and ended with the second survey in 1994. One thousand four hundred and twenty-eight apparently healthy middle-aged men were included in this survey. Data was collected from clinical examination; blood tests; spirometry; chest radiographs; ECG recordings; height and weight measures; and exercise performance on a stationary bicycle. The researchers defined "physically active" as exercising twice a week to the extent that caused sweating and shortness of breath. The results indicated an inverse relationship between physical activity and mortality, suggesting decreased fitness as a strong predictor of mortality.

There is an abundance of information to support the development of exercise programs for cardiovascular and general health, yet the majority of the population 
chooses not to comply with exercise recommendations. If the majority of healthy people are not persuaded by health benefits to engage in exercise, what does that mean to therapists hoping to convince their patients to engage in exercise? This information should encourage therapists to consider the underlying beliefs that determine a person's decision-making process for engaging in health behavior. There are several theories to explain the cognitive and perceptual underpinnings of behavior. This study focuses on self-efficacy as a theoretical basis for behavior, due to the abundance of studies in the literature citing positive associations between self-efficacy and physical activity (Ewart et al., 1983; Desmond et al., 1993; Cousins, 1996; Muto et al., 1996; Burke, 1997; Conn, 1998; Clark, 1999). Self-efficacy expectations are predictive of increase in physical activity. Alternative models of behavioral change include the Transtheoretical model (Prochaska and DiClemente, 1983), "lifestyle imbalances" (Marlatt, 1988), and "motive systems" (Kemp, 1988).

\section{Self-efficacy as theoretical framework}

It is important to the field of physical therapy that practitioners are aware of the underlying cognitive and perceptual factors affecting the patient's decision to exercise. This will allow therapists to choose the most effective method of persuasion at their disposal. A highly studied model for inducing behavioral change is Bandura's concept of self-efficacy. Self-efficacy has been shown to be significantly associated with exercise practices as well as intention to exercise (Ewart et al., 1983; Desmond et al., 1993; Cousins, 1996; Muto et al., 1996; Burke, 1997; Conn, 1998; Clark, 1999). Self-efficacy is 
now accepted as an important part of health care, and research indicates the usefulness of this concept to physical therapists (Moffett and Richardson, 1997).

A large body of work is focused on the concept of perceived self-efficacy. The theory of perceived self-efficacy is derived from Bandura's theoretical framework established to explain the emergence of coping behavior, the extent of effort used, and the length and duration an individual will engage in this behavior in the face of obstacles (Bandura, 1997).

Utilizing this theoretical framework, beliefs of self-efficacy for a given situation will affect an individual's initiation of an action as well as continuation of a course of action. People will avoid threatening situations if they believe they do not possess the coping skills, while they will engage in activities they believe they are capable of handling. If a person engages in threatening activities and perseveres, this allows for ample experiences that increase self-efficacy. Increased self-efficacy in turn will increase performance by enhancing intensity and persistence of effort (Bandura, 1997). In a clinical setting, this cognitive discrepancy may be used to explain the differences found in the performance of patients with similar physical abilities and similar diagnosis. The person with low self-efficacy may be unwilling to engage in exercise, depriving himself or herself of the necessary time to gain experience and skill mastery. There will be no chance for an increase in self-efficacy.

The foundation of self-efficacy is based on four major sources of information: performance accomplishments, vicarious experience, verbal persuasion, and emotional arousal (Bandura, 1977). Performance accomplishments are based on personal mastery experiences. Successful attempts at a skill will raise one's sense of mastery, while failure 
lowers this expectation, especially if errors occur at the initial development of a skill.

However, failures should not be viewed as entirely detrimental to the learning process. A failure that is later overcome through determination can act to strengthen persistence (Bandura, 1977). If a patient persists in attaining a goal through determined effort, there will be an increase in self-efficacy for the given activity, further motivating the patient to continue with efforts to reach his or her goal.

Vicarious experiences also serve as a source of information for determining levels of mastery. Observing someone else overcome obstacles and perform a similar task can increase the expectations of an observer that he or she can also successfully complete the task with increased effort. This source of building self-efficacy is not as effective as performance accomplishments (Bandura, 1977). Models that are similar to the individual in skill levels and other characteristics that increase the personal relevance of observed information can increase the effectiveness of modeling (Kadzin, 1973). For example, a 68 year-old patient in a cardiac rehabilitation program would have better results observing another senior demonstrating the exercises than observing a college athlete performing them.

Verbal persuasion is not as effective a source of information as performance accomplishments as a means of enhancing self-efficacy because it isn't derived from the individual's actual experiences. When using verbal persuasion to raise expectations of self-efficacy, it is important to strengthen environmental conditions to lead to an optimal performance outcome (Bandura, 1977). For example, if a patient was persuaded to believe that he or she could perform a certain task, and then subsequently failed, this may have the opposite effect and could discredit the use of verbal persuasion. It is interesting 
to note, that although this the least effective base for self-efficacy, it is the source utilized most often in a clinical physical therapy setting.

The final component for deriving levels of self-efficacy, emotional arousal, is utilized as information when an individual is coping with a difficult situation. An individual uses states of emotional arousal to gage levels of anxiety related to performing certain tasks (Bandura, 1977). High levels of arousal are more likely to interfere with a task; therefore competency expectations are more likely to occur with lessened states of arousal (Bandura, 1977). In a clinical setting, fear and anxiety of falling may induce a reaction that actually increases the risk of falling, perpetuating the anxiety and decreasing feelings of self-efficacy.

\section{Effects of self-efficacy on skill and exercise performance}

An efficacy expectation is a person's belief that he or she has the ability to engage in behavior necessary to produce the desired outcome (Bandura, 1977). Kempen (1999) studied the effects of physiological attributes on changes in disability in a communitybased sample of 575 low-functioning elderly residents for a two-year period. Kempin demonstrated that perceived control, or mastery, affected the incidence of disability in this population. Individual's possessing high perceived-control demonstrated no significant increase in disability in the two-year period of the study (Kempen, 1999).

Research by Ewart et al. (1983) with patients following myocardial infarction, determined that in the household setting, exercise intensity and duration were more highly correlated with self-efficacy than with peak heart rate. The researchers also found that individuals with low pretest self-efficacy who performed better on tests tended to 
have increased self-efficacy. The reverse was also true, that individuals with high pretest self-efficacy who performed less well on tests tended to have decreased self-efficacy (Ewart et al., 1983). This study emphasizes not only the correlation between self-efficacy and exercise, but also the importance in matching patient ability to exercise parameters for optimal results. If a patient's capacity is over-rated, and exercises prescribed too far beyond his or her capabilities, then the reduction of self-efficacy and subsequent confidence loss may decrease the patient's efforts at completing an exercise program.

Many studies demonstrate a correlation between high self-efficacy for physical activity and engaging in exercise (Ewart et al., 1983; Desmond et al., 1993; Cousins, 1996; Muto et al., 1996; Burke, 1997; Conn, 1998; Clark, 1999). There are also many studies on self-efficacy beliefs and exercise perceptions of older adults. Clark (1999) distributed a questionnaire among 771 socio-economically disadvantaged respondents, aged 55 or older. Lower self-efficacy was found to be associated with less physical activity. This questionnaire also revealed that participants engaged in an average of 65 minutes of physical activity per week. Conn (1998) collected data on lifelong leisure activity of 147 adults ages 65 to 100 years old. Self-efficacy expectations were found to have the strongest positive association with exercise behavior. The fact that self-efficacy beliefs are associated with exercise perceptions and performance levels for older adults is consistent with self-efficacy reflecting individuals' beliefs in their performance capabilities.

Muto et al. (1996) distributed a questionnaire to 761 healthy male workers in a manufacturing company in Japan, receiving responses from 515 employees. He found that regular physical activity was associated with increased self-efficacy. Other factors 
that were associated with regular exercise were support from colleagues, membership in a health club, and perceived benefits of exercise. Desmond et al. (1993) surveyed both white-collar and blue-collar workers, and also found that self-efficacy and perceived health status were the perceptual factors that predicted physical activity. Gecht et al. (1996) surveyed 68 individuals' ages 27 to 80 with arthritis from three Chicago area health care facilities. These researchers concluded that increased belief in the benefits of exercise and increased self-efficacy are associated with increased participation in exercise activities. These researchers also found that self-efficacy beliefs are positively associated with exercise performance levels for adults. This is consistent with self-efficacy theory reflecting individuals' beliefs in their capacity to perform exercises.

Horne (1994) surveyed 630 homemakers in rural Canada to determine their attitudes towards and practice of moderate activity. For active homemakers, self-efficacy, along with perceived social support, were predictors of future intentions to exercise. Cousins (1996) studied 327 women aged 70 to 98 to determine the reason for variance in exercise behavior. The two cognitive models that demonstrated associations with exercise activity were self-efficacy to exercise and social support to exercise. The fact that selfefficacy beliefs are associated with exercise perceptions and performance levels for women is consistent with self-efficacy reflecting individuals' beliefs in their performance capabilities.

\section{Models for behavioral modification}

Rates of compliance with exercise programs are similar to the rates of adherence for other behavioral modification programs such as smoking, alcohol/drug cessation, and 
weight loss (Dishman, 1985). Potentially then, some of the same behavioral modification techniques, and the strategies to affect this behavior, may apply to increasing exercise compliance. A major difference between exercise adherence and substance use is that for exercise, a low-frequency desired behavior is increased, while for substance use, a high frequency undesired behavior is extinguished. Simkin and Gross (1994) assessed coping responses in high-risk situations in which there might be a potential for exercise relapse amongst healthy women. Patterns of relapse were examined, and the researchers found that women who relapsed exhibited fewer behavioral and cognitive strategies for coping with high-risk scenarios than the women who maintained exercise behavior.

A model for behavioral modification techniques may be useful to increase exercise compliance. The goal of increased self-efficacy may possibly be reached by using techniques aimed at behavioral change. Prochaska and DiClemente (1983) applied an integrative model of behavioral change, the Transtheoretical model comprising five stages of change: pre-contemplation, contemplation, action, maintenance, and relapse. These stages were used to gage the process of change in individuals attempting to quit smoking. The researchers found that in the contemplative stage, subjects are most likely to respond to feedback and education about quitting smoking. During the action phase, subjects report relying more on helping relationships for support and understanding (Prochaska and Diclemente, 1983). With a clearer understanding of the process of change an individual engages in, it may be possible to tailor exercise programs for physical therapy patients according to their readiness to accept change. This may result in a difference in emphasis placed on the program dependent on the state of the individual's readiness to change. 
Bock et al. (1997) utilized the Transtheoretical model of change for 62 patients in a cardiac rehabilitation program. Researchers found that of the patients who regressed in the program by the 3-month follow-up, the results indicated significantly more negative decision balance scores, lower self-efficacy, and less engagement of behavioral processes of change, than those who did not regress. The researchers also found that patients' perceptions of the benefits of exercise predicted their adherence to the program, but did not find the change in cognitive process that occurs with self-changers in other settings. They attribute this to the different situation inherent in cardiac rehabilitation, which often occurs after hospitalization for a cardiac event, when a patient's motivation to change habits may be transitory or non-existent. The researchers concluded that tailoring an exercise program to individuals who are sedentary or inactive could increase patient compliance by focusing on patient's awareness of the benefits of exercise and reducing barriers to exercise.

Marlatt (1988) takes another approach to behavioral change. He considers readiness for behavioral changes in the context of lifestyle imbalances, in which an individual compiles a mental list of things they desire to do, and things they feel they should do. If the individual's list of compelled activities outweighs desired activities, then a lifestyle imbalance occurs. This will lead to a desire for self-gratification, in order to change the balance in favor of desired activity over those actions that are compulsory. Partaking of desired activity can take the form of cravings for forbidden substances or failure to exercise.

Kemp (1988) has devised a mathematical "motive system" based on a complex interplay of variables that include wants, beliefs, rewards, and costs. He also advises 
understanding that a person's belief $\mathrm{s}$ about his or her state of health may not be accurate or based in reality. He uses the example of a patient with a cerebral vascular accident (CVA) not being motivated in a rehabilitation setting because he believes that it would be impractical to struggle with his current physical condition. Unless that belief system is changed, a person with this perspective will not put forth the effort needed for optimal rehabilitation from this condition.

Models that emphasize behavioral changes that increase the frequency of desired behaviors are not exclusive of increasing self-efficacy. Bandura (1977) believes that people will avoid threatening situations if they believe they do not possess the coping skills, while they will engage in activities they believe they are capable of handling. If a person engages in threatening activities and perseveres, this allows for ample experiences that increase self-efficacy. Increased self-efficacy in turn will increase performance by enhancing intensity and persistence of effort. Therefore the increase in the behavior itself can result in an increase in self-efficacy for the behavior, leading to a further increase in the desired behavior. It is possible for the models of change and self-efficacy systems to act simultaneously, or have greater associations for different populations.

\section{Use of Positive Feedback}

The study by Sluijs et al. (1993) on exercise compliance in physical therapy investigated attitudes of the patient as well as those of the therapist. Audiotapes were made of patient-therapist interactions. The four variables related to compliance that were measured were extensiveness of therapist instructions (the number of remarks made about home exercise), patient ideas (the number of time therapists questioned patients on 
their condition), therapist-patient relationship (items such as therapists' concern for pain), and positive feedback (patients were questioned on therapists' expression of satisfaction with patient performance of exercise). In this study, the positive feedback patients perceived was the only variable significantly related to compliance with exercise programs.

A study by Crook et al. (1998) on adherence to group exercise found that feedback was an element of the program that was widely sought by the participants. Another study by Sluijs and Knibbe (1991) on the relationship of therapists and their patients found that positive feedback from the therapist or family member was an important factor in achieving short-term compliance.

Martin et al. (1984) utilized positive feedback in a study involving subjects running in pairs or in small groups while an instructor spoke with them. The instructors gave feedback on running styles to some of the participants and praised them for adhering to the program. This resulted in better class attendance and better exercise maintenance after 3 months. They also discovered that setting flexible exercise goals rather than fixed goals were associated with decreased attrition, increased attendance and better exercise maintenance after 3 months.

\section{Use of Lifestyle Activities}

As an alternative to structured exercise classes, the concept of "lifestyle activity" as a way to promote fitness has emerged. Activities are woven throughout the daily routine. Simple suggestions such as taking the stairs instead of elevators, parking at the 
far end of the parking lot, and even activities such as housework, gardening, and hobbies can be considered part of the daily routine.

Andersen et al. (1999) compared health outcomes in a group of obese women in a program of either lifestyle activity and diet or aerobic exercise and diet. The results demonstrated similar improvements in fitness, serum lipid levels, and blood pressure. At the one-year follow-up, the subjects in the lifestyle group maintained their weight loss better than the aerobic group. The authors attributed this to the longer lasting habits formed by the lifestyle group, which are easier to maintain than a structured exercise class. A study by Dunn et al. (1999) supports the hypothesis that behaviorally based lifestyle activity integration can produce measurable changes in cardio-respiratory fitness, blood pressure, and body fat composition equivalent to those found in a traditional exercise program. Results were maintained at two-year follow-up.

Perri et al. (1997) examined the effects of two types of exercise regimes on exercise participation, fitness, eating patterns, treatment adherence, and weight changes in 49 obese women during a year-long behavioral weight loss program. Participants engaged in either a group-based or home-based program, with both groups participating in a moderate-intensity walking program (30 minutes a day for 5 days a week). At the end of the program, the home-based program had better performance in exercise participation and treatment adherence.

A study by Jakicic et al. (1995) measured the effect of several short burst of exercise versus one long bout per day to determine if this would enhance exercise adherence and weight loss in overweight women. Both the control and experimental groups were instructed to perform 20 minutes (later progressing to 40 minutes) of 
exercise 5 days a week. The experimental group performed the exercises in 10-minute bouts throughout the day, while the control group exercised for the full time. The experimental group reported exercising for a greater number of days ( 87.3 days) than the control group (69.1), and for longer duration (223.8 minutes per week) than the control group (188.2 minutes per week). There was also a trend for greater weight loss in the experimental group (8.9 pounds) versus the control group (6.4 pounds).

\section{Gender Related Barriers to Exercise}

Barriers to exercise can be affected by many factors such as gender, socioeconomic status, and age. Scharff et al. (1999) designed a questionnaire completed by 653 women seeking medical attention at four community-based family medicine clinics. The researchers found that although younger women had high self-efficacy for exercise, they reported the highest number of barriers, among them child care. Older women reported health as the most common motivator for exercise, but were the least likely to exercise.

Lieberman et al. (1998) studied gender differences in the perceived barriers to attendance in cardiac rehabilitation programs, and found that although both sexes rated concomitant illness, transportation problems, and inconvenient timing of the program as the most important barriers to attendance, women rated concomitant illness as a more powerful barrier than men, and were more likely to be influenced by encouragement to attend from their adult children.

The presence of younger children, however, can have a diminishing effect on exercise activity. In a study by Verhoef and Love (1992), although both childless women 
and mothers perceived similar benefits to exercising, mothers were much less active than women without children, especially for those under forty years of age. After forty, the differences decreased due to a decline in exercise by the more active women. The study also revealed that mothers perceived more barriers than did women without children.

Child care as a hindrance to exercise is not limited to women. Naslund et al. (1996) studied compliance rates of 118 healthy middle age men with risk factors for coronary artery disease with a 6-month diet and exercise regimen. Data was collected through medical examinations, interviews, and questionnaires. The researchers found an association between poor compliance with the exercise program, and younger age and having children at home.

\section{$\underline{\text { Socioeconomic Barriers to Exercise }}$}

There are also socioeconomic and ethnic factors involved in perceived barriers to exercise. Harnack et al. (1999) studied diet and physical activity patterns of Lakota Indian adults on the Indian reservations in South Dakota. Lack of child care, lack of time, and safety concerns were the most common perceived barriers listed. Nies et al. (1999) recruited African American women ages 35-50, and found similarities in the barriers listed: lack of child care, unsafe neighborhoods, competing responsibilities, fatigue, no person to exercise with, lack of motivation, lack of space at home, and inability to use exercise facilities at work. A study by Eyler et al. (1998) on minority women, confirmed Nies' findings, listing environmental barriers to exercise as safety, availability, and costs. The researchers found personal barriers most cited to be lack of time, health concerns, and lack of motivation. Jones and Nies (1996) conducted a study to determine the barriers 
perceived by African American women over 60 years of age. They found that exercise availability and accessibility were the most critical issues. In another study by Nies et al. (1998) conducted with European American women, the major barriers to exercise were found to be lack of family support and scheduling conflicts. Sternfield et al. (1999) randomly surveyed a diverse population of 2,636 women members of a health maintenance organization. The factors constituting the greatest barrier to exercise included Hispanic ethnicity, marriage, having young children at home, and greater time constraints.

\section{Age-related barriers to exercise}

Perceived obstacles to exercise can change over time. In the Pilot Survey of the Fitness of Australians, conducted by Booth at al. (1997) on 2,298 adults, the main barriers to exercise for those over 60 were complaints of injury and poor health. For those under 60 , lack of time and motivation, and child care responsibilities were most commonly cited as barriers to activity. A meta-analysis by Rhodes et al. (1999) of twenty-seven cross-sectional and fourteen longitudinal studies of factors associated with regular exercise among older adults found similar barriers to exercise as Booth, with perceived physical frailty and poor health proving the greatest barriers.

Research by Dunlap and Barry (1999) reveals those personal barriers to exercise for older adults include lack of time, discomfort, fear of injury, inertia (sedentary practice during lifetime), isolation (poor social support), and misconceptions (patients may feel their choices of exercise are limited to activities such as jogging). Environmental barriers listed are access to and cost of fitness facilities and climate conditions (in northern 
climates, inclement weather and unsafe outdoor conditions due to ice and snow can limit exercise access, while extremes of heat and humidity are potential barriers in warmer climates).

\section{Additional barriers to exercise}

A study by Oldridge (1998) lists other factors as reasons cited for not participating in exercise programs. These reasons included inconvenience, time conflicts, inaccessibility and lack of spousal support. In a study by Anderson (1999) of 52 overweight, sedentary patients who were beginning a weight loss program, the four greatest barriers to exercise were; lack of time, embarrassment at taking part in the activity, inability to exercise vigorously, and lack of enjoyment of exercise. Studies by Dishman and Sallis (1985) cite lack of time, lack of social support, bad weather, disruptions in routine, lack of access to facilities, and dislike of strenuous exercise.

A lack of time has been reported as the biggest obstacle to engaging in planned exercise (Johnson et al. 1990; Godin et al., 1991; Bull et al., 1995; Andersen 1999; Dunn et al., 1999; Harnack et al., 1999). A study by Bull et al. (1995) of 789 general practitioners mentioned lack of time as the most frequent barrier to physical activity reported by patients ( $47 \%$ response) followed by insufficient educational material $(29 \%)$ and preference for drug treatment (27\%) Johnson et al. (1990) utilized a communitybased sample of women to determine the factors affecting exercise habits. The lack of time was reported to be the most significant factor affecting exercise behavior.

Sluijus et al. (1993) surveyed both patients and physical therapists to determine if patient compliance was related to the type of illness the patient had, the patient's attitude, 
or to the therapists behavior. They found that patients whose illness resulted in greater disability complied better with home exercise programs than those with less disability. The researchers found that the strongest factor in noncompliance is the barriers patients perceive. The barriers most cited were too little time, exercises not fitting into daily routine, and forgetting to exercise. The greatest factor predicting patient compliance was the positive feedback patients receive.

Although numerous benefits of exercise have been documented in the literature, the majority of the population does not engage in enough physical activity to meet the American College of Sports Medicine recommendations for moderate activity (American College of Sports Medicine, 1998b). By considering theories of self-efficacy and behavioral change, it may be possible to understand the cognitive and perceptual processes that determine a person's decision to make a behavioral change. Research demonstrates that increased self-efficacy for an activity is predictive of an increase in performance of that activity (Ewart et al., 1983; Desmond et al., 1993; Cousins, 1996; Muto et al., 1996; Burke, 1997; Conn, 1998; Clark, 1999). Methods to increase selfefficacy and decrease patients' perceived barriers should lead to an increase in patient compliance with home exercise programs.

It is possible to increase patient compliance by eliminating factors that act as barriers to compliance. A lack of time has been the most consistently stated barrier to exercise across the studies. One method to alleviate this source of noncompliance is to prescribe lifestyle activities as part of a home exercise program. Lifestyle activity exercises also have the advantage of fitting exercises into a patient's schedule without incurring large changes in routine behavior. Provisions for child care and transportation 
to facilities, community access at facilities, and social support are methods to increase compliance. Increasing patient self-efficacy for exercise through methods such as utilizing positive feedback can also act to increase patient compliance. 


\section{CHAPTER III}

\section{Methodology}

\section{Objectives and Research Questions}

The objective of this study was to determine physical therapists use of methods that have been shown to increase patient compliance, and to determine if the reasons patients routinely given for not complying with a home exercise program are similar to those reasons found by other studies. Another purpose of this study was to describe the association, if any, between therapists' participation in exercise and/or lifestyle changes and their method of exercise prescription.

The research questions asked were:

1. Do physical therapists routinely suggest lifestyle activities as part of an exercise program?

2. Do physical therapists utilize feedback to increase patient compliance with home exercise programs?

3. Are the reasons patients give physical therapists for noncompliance with home exercise programs similar to those found in the literature?

4. Are there any associations between therapists' participation in exercise and/or lifestyle changes and their method of exercise prescription?

\section{$\underline{\text { Subjects }}$}

Subjects in the study were all self-identified registered physical therapists and members of the American Physical Therapy Association (APTA). The subjects 
completing the questionnaire represent a sample of convenience, self-selected by attending the national meeting of the APTA Combined Sections meeting in New Orleans, Louisiana on February $4^{\text {th }}, 2000$. Inclusion criteria included: (1) participants were registered physical therapists; (2) only those therapists utilizing exercise programs, and (3) membership in the APTA. A cover letter addressed the reason for the questionnaire. The results remained anonymous. Participants were given the choice of receiving an abstract of the study upon its completion.

\section{Setting}

Subjects were surveyed while attending the APTA 2000 Combined Sections meeting in New Orleans, Louisiana on February $4^{\text {th }}, 2000$. The primary purpose of the subjects was to attend this meeting, and none of the subjects knew in advance that they would be surveyed. The APTA is a national organization, and members reside in various areas throughout the United States. Completion of the survey was done so on a voluntary basis after it was distributed to the subjects by the researcher.

\section{Instrument Design}

The only intervention used was a questionnaire consisting of three demographic questions, eight close-ended questions, and one open-ended question (Salant and Dillman, 1994) that was developed by the researcher. Demographic items included state of residence, age, and years of practice as a physical therapist. Questions one and two required answers in percentages, and question three required rank ordering of available answers. Questions numbers four through six are formatted in a 5-point Likert scale $(1=$ strongly agree, $5=$ strongly disagree). Two of the respondents answered the questions orally, and the researcher recorded their responses. If a given range was stated as an 
answer, the highest end of the range was consistently recorded as the answer. For the first question on data, years worked as a physical therapist, answers of a fraction of a year were rounded upwards to the nearest year.

The questionnaire was developed after a review of the literature to determine if: (1) therapists practiced methods to increase compliance; (2) reasons stated by patients to their therapists for their noncompliance with exercise programs are similar to those found by previous studies, and (3) there any associations between therapists' participation in exercise and/or lifestyle changes and their method of exercise prescription?

See Appendix A for copy of the original questionnaire.

\section{Procedure}

All APTA members requested to complete the questionnaire did so voluntarily after being approached by the researcher with a copy of the questionnaire on a clipboard. Participants were asked if they: (1) were practicing physical therapists, and (2) prescribed home exercise routines for their patients. Participants completed the seventy-three handdelivered questionnaires on-site. The researcher remained available to answer any questions the subjects had about the questionnaire. The purpose of the study was not discussed until the questionnaire was completed to avoid prejudice in the response. Data Analysis

Data was entered on a Microsoft Excel Spread Sheet for Windows and analyzed using the Statistical Package for the Social Sciences (SPSS) for Windows version 8.0. Descriptive statistics were generated for each variable. Chi-Square analyses were used to evaluate the association between several variables. 


\section{CHAPTER 1V}

\section{$\underline{\text { Results }}$}

\section{Characteristics of the Survey Respondents}

Seventy-three physical therapists responded to the survey, residing in 27 states in the United States and one respondent residing in the US Virgin Isles. The state of residence listed most often was Texas $(12.3 \%)$, followed by Pennsylvania $(8.2 \%)$. The years of practice as a physical therapist ranged from less than one year to 36 years, with a median of 12.0 years. The ages ranged from 23 to 63 years of age, with a median age of 38.5 years. Summary of years of practice as a physical therapist and age can be found in the Tables 1 and 2 .

Table 1

Years of experience as a physical therapist

\begin{tabular}{lll}
\hline Years & n & $\%$ \\
\hline $1-5$ & 20 & 27.3 \\
$6-10$ & 13 & 17.7 \\
$11-15$ & 11 & 15.1 \\
$16-20$ & 11 & 15.1 \\
$21-25$ & 9 & 12.4 \\
$26-30$ & 7 & 9.6 \\
$31-36$ & 2 & 2.8 \\
\hline Total & 73 & 100 \\
\hline
\end{tabular}

Note. $\underline{\underline{n}}=$ the total number of respondents. 
Table 2

Age of therapist

\begin{tabular}{lll}
\hline Years & $\underline{\mathrm{n}}$ & $\%$ \\
\hline $23-28$ & 11 & 15 \\
$29-34$ & 14 & 19.2 \\
$35-40$ & 18 & 24.6 \\
$41-46$ & 13 & 17.9 \\
$47-52$ & 10 & 13.7 \\
$53-58$ & 3 & 4.1 \\
$59-63$ & 3 & 4.1 \\
\hline Total & $72^{*}$ & $98.6^{*}$ \\
\hline
\end{tabular}

Note: $\underline{n}=$ the total number of respondents.

* One respondent did not list age. Therefore $\underline{\underline{n}}=72$ for this data. 
Question 1: Approximately what percentage of your patients receive home exercise programs?

The answer of " $75 \%$ or greater" was chosen by $80.5 \%(\underline{n}=58)$. See Table 3 for summary of this information.

Table 3

Percentage of patients receiving home exercise programs

\begin{tabular}{lll}
\hline \% of patients & $\underline{\mathrm{n}}$ & \% of responses \\
\hline $0-25$ & 4 & 5.6 \\
$26-50$ & 5 & 6.9 \\
$51-74$ & 5 & 6.9 \\
$75-100$ & 58 & 80.5 \\
\hline Total & $72^{*}$ & $99.9^{* *}$ \\
\hline
\end{tabular}

Note. $\underline{n}=$ the total number of respondents.

*One respondent did not answer this question, therefore $\underline{\underline{n}}=72$ for this question. Number not equal to 100 due to rounding estimates. 
Question 2: Approximately what percentage of your patients receive suggestions of lifestyle activities as part of their exercise programs?

The answer of " $75 \%$ or greater" was chosen by $52 \%(39)$, indicating that approximately half of the therapist include lifestyle activity suggestions in their home exercise programs for most of their patients. See Table 4 for summary of this information.

Table 4

Percentage of patients receiving lifestyle activity suggestions

\begin{tabular}{lll}
\hline$\%$ of patients & $\underline{\mathrm{n}}$ & $\%$ of total \\
\hline $0-25$ & 13 & 18.1 \\
$26-50$ & 16 & 22.2 \\
$51-74$ & 4 & 5.5 \\
$75-100$ & 39 & 54.2 \\
\hline Total & $72^{*}$ & 100 \\
\hline
\end{tabular}

Note. $\underline{n}=$ the total number of respondents.

*One respondent did not answer this question, $\underline{\mathrm{n}}=72$ for this question. 
Question 3 required the therapist to rank order the responses according to how often the response was used by patients for non-compliance. See table 5 for first ranked responses to this question.

\section{Table 5}

First ranked reason patients state for exercise noncompliance

\begin{tabular}{lll}
\hline Response: & $\underline{\mathrm{n}}$ & $\%$ \\
\hline Inconvenient & 7 & 9.6 \\
Not enough time & 40 & 54.8 \\
No motivation & 7 & 9.6 \\
Too strenuous & 2 & 2.7 \\
Cannot perform exercise & 6 & 8.2 \\
Pain & 11 & 15.1 \\
\hline Total & 73 & 100 \\
\hline
\end{tabular}

Note. $\underline{n}=$ the total number of respondents. 
Question 4: I have found that increasing positive feedback has increased compliance with exercise programs in my patient population.

This question was answered either somewhat or strongly agree by $90.4 \%(\underline{n}=66)$.

See Table 6 for summary of this information.

Table 6

Increasing positive feedback increases patient compliance

\begin{tabular}{lll}
\hline Response: & $\underline{n}$ & $\%$ \\
\hline Strongly agree & 23 & 31.5 \\
Somewhat agree & 43 & 58.9 \\
Undecided & 6 & 8.2 \\
Somewhat disagree & 1 & 1.4 \\
Strongly disagree & 0 & 0 \\
\hline Total & 73 & 100 \\
\hline
\end{tabular}

Note. $\mathrm{n}=$ number of respondents. 
Question 5: I ask all my patients for feedback on how they feel the exercises I have prescribed have been effective.

This question was answered either somewhat or strongly agree by $93.2 \%(\underline{n}=68)$.

See table 7 for summary of this information.

Table 7

Patients received feedback on exercise effectiveness

\begin{tabular}{lll}
\hline Response: & $\underline{\mathrm{n}}$ & $\%$ \\
\hline Strongly agree & 51 & 69.9 \\
Somewhat agree & 17 & 23.3 \\
Undecided & 1 & 1.4 \\
Somewhat disagree & 3 & 4.1 \\
Strongly disagree & 1 & 1.4 \\
\hline Total & 73 & 100 \\
\hline
\end{tabular}

Note. $\underline{n}=$ number of respondents. 
Question 6: I often mention ways to make 'boring' exercises more amusing to patients by suggesting methods such as watching television, listening to the radio or having a buddy while exercising.

This question was answered either somewhat or strongly agree by $87.7 \%(\underline{n}=64)$.

See Table 8 for the summary of this information.

Table 8

Therapist using distraction techniques

Response: Therapists using

Distraction techniques

Strongly agree

$\underline{\mathrm{n}} \quad \%$

30

41.1

Somewhat agree

46.6

Undecided

4

5.5

Somewhat disagree

4

5.5

Strongly disagree

Total

Note. $\underline{n}=$ number of respondents. 
Question 7: I engage in an exercise routine lasting at least 20 minutes for 3 times a week or more.

This question was answered either somewhat or strongly agree by $78.1 \%$. $(\underline{n}=57)$. See table 9 for summary of this information.

Table 9

Therapists engaged in weekly exercise routine

\begin{tabular}{lll}
\hline Response: & $\underline{\mathrm{n}}$ & $\%$ \\
\hline Strongly agree & 40 & 54.8 \\
Somewhat agree & 17 & 23.3 \\
Undecided & 1 & 1.4 \\
Somewhat disagree & 11 & 15.1 \\
Strongly disagree & 4 & 5.5 \\
\hline Total & 73 & 100 \\
\hline
\end{tabular}

Note. $\underline{n}=$ number of respondents. 
Question 8: I have made a lifestyle change for health improvements, such as a change in eating habits, smoking cessation, or starting an exercise program in the last three years.

This question was answered either somewhat or strongly agree by $72.6 \%(\underline{n}=53)$. See table 10 for summary of this information.

Table 10

Therapists making lifestyle changes for health improvement

\begin{tabular}{lll}
\hline Response: & $\underline{\mathrm{n}}$ & $\%$ \\
\hline Strongly agree & 33 & 45.2 \\
Somewhat agree & 20 & 27.4 \\
Undecided & 3 & 4.1 \\
Somewhat disagree & 8 & 11.0 \\
Strongly disagree & 9 & 12.3 \\
\hline Total & 73 & 100 \\
\hline
\end{tabular}

Note. $\underline{n}=$ number of respondents. 


\section{Pearson Chi-Square values}

Pearson Chi-Square values were calculated to see if there was a significant relationship between therapists personally engaging in lifestyle changes and prescribing lifestyle activities to their patients, $\mathrm{p}$-value is .015 . The $\mathrm{p}<05$, indicates that the results are statistically significant. The results show $47.2 \%(\underline{n}=34)$ of therapists making lifestyle changes give over half of their patients suggestions of lifestyle activities.

There were no significant relationships found between the following variables using Pearson Chi-Square analyses: (1) therapists engaging in weekly exercise and prescribing lifestyle activities to their patients (p-value .228); (2) therapists utilizing distraction techniques and prescribing lifestyle activities (p-value .492); (3) therapists utilizing distraction techniques and personally engaging in lifestyle change (p-value is $.527)$; and therapists engaging in weekly exercise and age of therapist (p-value .561).

The last question in the survey was an open-ended question: What is the most important advice you would give a physical therapy student regarding the best way to achieve patient compliance?

A summary of responses is found in Table 11. 
Table 11

Advice to increase patient compliance

\begin{tabular}{lll}
\hline Response & $\underline{\mathrm{n}}$ & $\%$ \\
\hline Make exercises fun/realistic & 8 & 8.7 \\
Limit number of exercises & 7 & 7.6 \\
Repeat home exercises & 7 & 7.6 \\
Discuss patient goals & 7 & 7.6 \\
Exercise importance and benefits & 7 & 7.6 \\
Exercise scheduling & 7 & 7.6 \\
Simple exercises & 6 & 6.5 \\
Positive feedback/results & 6 & 6.5 \\
Tailor exercise & 5 & 5.4 \\
Encourage/motivate patient & 5 & 5.4 \\
Include family in treatment & 5 & 5.4 \\
Written home exercise program & 4 & 4.3 \\
Therapist as example & 3 & 3.2 \\
Unique responses* & 15 & 16.3 \\
\hline Totals & 92 & 100 \\
\hline Noten
\end{tabular}

Note. $\underline{n}=$ number of responses

Number of responses $>73$, some therapist gave $>1$ response.

*Unique responses listed in text, these items had only 1 response.

There were also several unique responses $(15 \%)$, such as the reminder to students to consider the impact of SES (socioeconomic status) and ethno-cultural differences in patient care; threaten the patient; use of a model; persistence; patient empowerment; talking to patient like your own mother; pay the patient; positive attitude of the therapist; use of lifestyle exercises; match options to ability; listen to the patient; maintain interest; be supportive; and use of diversion during exercise. 


\section{CHAPTER V}

\section{Discussion}

The purpose of this study was to determine physical therapists: (1) utilization of methods to increase compliance with home exercise programs, and (2) perceptions of barriers patients have to home exercise programs.

The secondary purpose of this study is to describe the association, if any, between therapists' participation in exercise and/or lifestyle changes and the factors listed above. Home exercise programs

Eighty percent of the therapists responded that they assigned home exercise programs to $75 \%$ or more of their patients. These therapists are utilizing home exercise programs for a large percentage of their patients. Since utilizing home exercise programs was an inclusion criterion in the study, this is an expected result. The fact that therapists are utilizing these programs for such a high percentage of their patients represents a significant reliance on home exercise as part of the treatment program by the physical therapists. Therefore, increased efficacy of the home exercise through enhanced patient compliance has potential to enrich the entire treatment process.

\section{Lifestyle activities}

Fifty-two percent of the therapists responded that they include lifestyle activity suggestions in their home exercise programs to $75 \%$ or more of their patients. This indicates that approximately half of the therapists include these suggestions to the majority of their patients. This data does indicate that a high percentage of lifestyle activity recommendations are being made by physical therapists to their patients 
Advantages to lifestyle activities for the patient include reduced financial and time costs incurred by attendance at an exercise facility, which may have a prohibited effect on a patient's intention to exercise. The American College of Sports Medicine has recommended that individuals try to accumulate at least 30 minutes of moderate physical activity on most days (American College of Sports Medicine, 1998b). By breaking up the activity throughout the day, it may allow for more individuals to meet these suggestions.

Lifestyle recommendations have an advantage over structured exercise programs because of the more flexible scheduling arrangements available through lifestyle exercise prescription. The patient does not have to worry about arriving at a facility prior to closure, or travel time to and from the facility. A factor as simple as reducing the amount of time necessary to complete the activity may make the difference between undertaking an exercise or postponing it to a more convenient time. As the studies by Andersen et al. (1999) and also by Dunn (1999) reveal, integration of lifestyle activities can have as important an impact on fitness levels as traditional structured exercise programs.

\section{Patient reasons for noncompliance}

The response of "not enough time" as the most frequently cited reason for patient non-compliance is consistent with previously cited studies (Johnson et al. 1990;Godin et al., 1991; Bull et al., 1995; Andersen 1999; Dunn et al., 1999; Harnack et al., 1999). In a study by Godin et al. (1991) the researchers presented a questionnaire to 161 cardiac patients on intentions to exercise. The researchers found that the perception of difficulties with time management was a factor associated with low intention to exercise. This study is in agreement with research by Johnson and Heller (1998) in a longitudinal study of 459 patients discharged from six public hospitals in Australia with a diagnosis of either acute 
myocardial infarction or angina. The researchers determined that the cardiac patients' time constraints and perceptions of the benefits of home exercise were predictive of adherence to regular home exercise six months after discharge from the hospital.

The responses of "no motivation" (Harnack et al., 1999, Eyler et al., 1998) "too strenuous" (Dishman and Sallis, 1998) "cannot perform exercises (Dishman and Sallis, 1998), and "pain" (Dunlap and Barry, 1999) are also documented in the literature as reasons cited by patients for non-compliance in home exercise programs.

Other reasons listed by therapist include no function; lost handout; forgot exercises; requires assistance; exercise is not the "quick fix"; poor proprioception; and uncertainty about correctness of exercise performance.

Increasing positive feedback to increase patient compliance

This question was answered either somewhat or strongly agree by $90 \%$, demonstrating utilization of positive feedback to elicit enhanced compliance from patients. The review of the literature revealed that several studies found positive feedback enhanced patient compliance. The study by Sluijs et al. (1993) on exercise compliance in physical therapy found that positive feedback to patients was the only variable significantly related to compliance with exercise programs. A study by Crook on adherence to group exercise found that feedback was an element of the program that was widely sought by the participants. Another study by Sluijus and Knibbe (1991) on the relationship of therapists and their patients found that positive feedback from the therapist or family member was an important factor in achieving short-term compliance.

Asking patients for feedback on exercise effectiveness 
This question was answered either somewhat or strongly agree by $93 \%$. The majority of the therapists in this study take advantage of patient input to build a stronger patient-provider relationship. The status of the provider-patient relationship has been demonstrated to have an effect on patient compliance. A study by Davis (1968) demonstrates that certain patterns of communication are associated with patient's failure to comply with the physician's advice. Interactions that can lead to such negative consequences include a scenario in which the physician acts formal, rejecting, or controlling, disagrees with the patient, or interviews the patient at length without subsequent feedback. An early study by Becker and Maiman (1975) concerning the factors affecting patient adherence to medical recommendations include patient expectations being met, the provider asking about and respecting all the patient's concerns, and providing responsive information about the patient's condition and progress.

Therapist suggesting distraction techniques

This question was answered either somewhat or strongly agree by $87 \%$. Many people have been sedentary for a large portion of their lives, and have had little practice compiling a history of positive exercise experiences. They may actually associate exercise with negative factors, such as muscular pain, shortness of breath, and increased heart rate. A person may interpret these signs as detrimental to his or her health, and discontinue exercise. Other factors such as boredom, fear of risk of injury, embarrassment caused by their present physical condition in a gym environment, and losing time away from family pursuits and more pleasurable activities can also be reasons to discontinue an exercise program (Dishman, 1988). 
Other strategies to reduce attrition from exercise programs include cognitive restructuring. This is an attempt to eliminate negative thoughts about exercise, as it relates to such issues as fatigue, boredom, and pain. Instead of letting one's mind dwell on thoughts such as "this is boring" or "I am feeling so tired," participants are taught to stop those thoughts and concentrate on something more pleasant. Dissociative strategies are also used, attempts to disengage body and mind through use of distraction. Martin et al. (1984) have found this technique useful in enhancing exercise programs after the termination of classes. These techniques are used to actively alter the thought process so that the "here and now" is not the primary focus, and thoughts of more gratifying activities predominate. Other methods include telephone, mail contact, and external cognitive aids. McCauley et al. (1993) suggest follow-up booster calls, prompts to action, and meetings of exercise groups to maintain the increases in activity gained during an exercise program. The researchers also suggest the formation of smaller groups within an exercise program to meet during the program to continue activity once the program is finished.

\section{Therapist engaging in weekly exercise}

This question was answered either somewhat or strongly agree by $78 \%$. This represents a majority of the therapist leading an active lifestyle. Research in the literature by Harsha et al. (1996) demonstrated a link between physician characteristics and patient willingness to comply with exercise recommendations. Associations for greater influence to exercise existed between patients with higher education levels and characteristics of the physician including appropriate weight maintenance and non-smoking. For patients 
who regularly exercise, there was a positive influence in their exercise adherence due to the physician characteristics of appropriate weight and personal exercise regimen. Therapists engaging in lifestyle changes

The question of therapists engaging in lifestyle changes were answered either somewhat or strongly agree by $72 \%$. This indicates a high percentage of the population of physical therapists surveyed participating in lifestyle changes to enhance their health.

$\underline{\text { Relationships between therapists behavior and exercise prescription }}$

The secondary purpose of this study is to describe the association between therapists' participation in lifestyle changes and their methods to solicit enhanced patient participation. A significant association exists between suggesting lifestyle activities and personally engaging in a lifestyle changes $(p=.015)$.

The present study supports the belief that physical therapists that have personally engaged in a lifestyle change will suggest lifestyle activities more often to their patients when designing home exercise programs. Whether this represents a deeper understanding of behavioral modification concepts, diverse patient populations, or a broader definition of what constitutes exercise is still conjectural.

The finding is in agreement with a study by Walsh et al. (1999) of one hundred and seventy-five physicians, which found that only $14 \%$ prescribed exercise for more than half their patients. Of these physicians, those who felt they were successful in changing behavior were more likely to ask about and counsel about exercise. In this study, self-efficacy for promoting change was associated with an increase in the behavior of suggesting exercise (behavioral change). 
Although the study by Walsh et al. (1999) involved physicians, whose primary specialty is not exercise prescription, there may be a generalized tendency for confidence in the ability to change behavior resulting in a greater number of attempts to change behavior. This success may then increase the self-efficacy for promoting behavioral change. The process of engaging in behavioral change could lead to increased selfefficacy for promoting change in others. Those individuals successfully changing their own behaviors may have greater belief in their ability to affect behavioral change in others, and therefore affect these changes.

No significant association was found between personally engaging in exercise and suggesting lifestyle activities $(p=.228)$. This seems to be in contradiction to a study by McKenna et al. (1998) supporting the association between exercise promotion and personal exercise routines in a sample of physicians and nurses. They found that physicians in the action or maintenance stage of changing their own exercise routines are three times more likely to promote the same behavior in their patients than those physicians in any of the other stages. For nurses, the likelihood of promoting change in these stages is even stronger, the result a four-fold increase in the likelihood of promoting exercise behavior.

The absence of association between lifestyle activity promotion and personal exercise routine may be due to the fact that exercise prescription lies within the primary domain of a physical therapist, as opposed to its secondary association with doctors and nurses. The other health care providers that actually engage in exercise may feel more confident in prescribing exercise, while the therapist have all had training in prescribing 
exercise routines. There could also be no association between physical therapists personal exercise goals and the exercise programs they endorse for patients.

There is also the time limitation of only including lifestyle changes being made in the prior three years. Some individuals may have made behavioral changes beyond this time frame, and the results from associations between exercise routines and lifestyle changes may have been different. Another factor could be the behavioral change the therapist made was not specified. It could have been a change in diet, smoking cessation, or exercise. Perhaps more specific information, such as a second question regarding the type of change, may have yielded additional information. A specific change related to exercise might have shown an association.

No association existed between therapists' use of distraction techniques and prescribing lifestyle activities $(p=.492)$. Perhaps the therapists engaging in personal changes did not use the stated behavioral techniques. Conversely, the therapist not engaging in lifestyle changes may have found these techniques useful for their patients.

No significant association was demonstrated between therapist exercising weekly and age. This demonstrates continued activity levels throughout the lifetime for physical therapists. It would be interesting to see how physical therapists rated against other health care providers in terms of physical activity levels.

No significant association was demonstrated between therapists prescribing distraction techniques and engaging in lifestyle changes $(p=.527)$. There were trends towards answering either strongly or somewhat agree to both questions by $64.3 \%(\underline{\mathrm{n}}=$ 47). Although statistical analysis doesn't demonstrate a significant association, there is a tendency for therapists engaging in lifestyle changes to use behavioral techniques to 
make exercises more amusing to their patients. This would corroborate a possible association between an increase in self-efficacy for change generated by personally engaging in a lifestyle change and engaging in behavior that fosters change.

$\underline{\text { Responses to advice to physical therapy students to achieve patient compliance }}$

Therapists suggested making the exercises fun and/or realistic. A study by Resnick (1996) suggests humor and fun as methods to increase patient compliance with an exercise program. Gage and Polatajko (1994), in a study on enhancing occupational performance, believe that to increase self-efficacy for a given task, actually performing the task is the most beneficial activity. They suggest that therapists use realistic activities that are used in the context of the environment they will be needed in. The authors question the use of pegboards and puzzles in the ability to change perceived self-efficacy for performance skills in real-life environments.

The researchers implicate lack of realistic experience as a reason for difficulties patients encounter when returning home to live independently. If the patient hasn't engaged in enough activities to simulate the living environment, self-efficacy expectations may not be sufficiently high enough for independent achievement. The researchers endorse the use of simulated environments to enhance personal performance accomplishments that will raise self-efficacy expectations.

Therapists considered limiting the number of exercises prescribed in the home exercise program to be of primary importance. Studies in the literature support this concept. Henry et al. (1998) conducted a study to determine if older adults comply and perform better (as measured by correct postural alignment, decreased necessity for 
cueing, and displaying controlled, coordinated, continuous movement during exercise) with fewer exercises. The researchers assigned strengthening exercises and asked subjects to report the number of repetitions performed each day. The group that was assigned the lowest number of exercises (2) performed them better than the group assigned the greatest number of exercises (8).

Therapists also suggested repetition of the home exercise program as the best method to achieve patient compliance. A study by Chen et al. (1999) on factors that influence patient compliance with home exercise programs, suggests that therapists have the ability to induce more accurate and consistent follow-through from patients. The researchers suggest that this can be accomplished by periodic demonstration of the home exercise program to allow for increased feedback on exercise performance.

Therapists suggested discussing patient goals to achieve patient compliance. An investigation by Becker and Maimon (1980) on behavioral determinants of patient compliance demonstrates that when the health provider and patient substantially agree on the specifics of a health regimen, patient compliance increases. The study by Chen et al. (1999) suggest that greater self responsibility for health outcomes from the patient will result if therapists encouraged greater participation from patients in treatment planning, problem solving, and goal setting.

Therapists suggested fitting exercises into patients' schedules. One of the disadvantages to exercising noticed most frequently in the studies involving women appeared to be having children at home (Verhoef and Love, 1992; Harnack et al., 1999; Nies et al., 1999; Scharff et al., 1999). The difficulty and expense of child care may leave women, as the majority of primary caretakers for children, at a disadvantage to gaining 
access to exercise facilities. Even if the facilities exist, some women may feel overburdened with the myriad of other responsibilities connected to childcare and possibly care for an aging parent. For these women, the therapist may gain increased compliance by adjusting the exercise routine to the work schedule, by suggesting lifestyle activities or prescribing shorter bouts of exercise that are more readily fit into a busy schedule.

Therapists suggested making exercises simple. Research by Duncbar-Jacob et al. (1991) on managing medical regimes, found that the more complex the prescribed regime is in number of behaviors and the longer the duration, the greater the increase in likelihood that adherence will decline over time. This problem is magnified in a patient population with multiple medical complaints. The patients may be instructed by their doctors to quit smoking, change their diets, start or increase their medications, and start exercising. Each behavior requires changes in aspects of lifestyle that the individual may be habituated to.

The term simplicity can also be of use to describe the language used to explain treatment conditions to the patient. The use of technical language can be misleading for patients. A breakdown of communication can result in the use of unfamiliar terms. In a study involving comprehension of written prescriptions by Mazullo et al. (1974) 25\% of the subjects understood the instructions "as needed for water retention" to mean that the pills would cause water retention. It is possible that even phrases therapists may consider innocuous may be subject to misinterpretation.

Therapists suggested use of positive feedback /results. Martin and Tubbert (1984) believe that reinforcement during or shortly after the exercise behavior will aid in 
increased compliance in a cardiac rehabilitation program. They suggest uplifting messages by the therapist supporting efforts at exercise are a sound strategy for increased compliance.

Therapists suggested encouraging or motivating patients. Resnick (1996) studied factors that serve as motivation in geriatric physical and occupational therapy. Encouragement from staff, setting goals, humor, and caring relationships were reported as some of the factors that led to increased motivation.

Oakes et al. (1970) retrospectively studied the influence of family members on the use of a hand-resting splint on patients with rheumatoid arthritis. Patients who felt their family members expected them to wear the splint were more likely to comply with the treatment regime. Heinzelmann and Bagley (1970) report on the response of a preventative health program for sedentary men 45-59 years old at risk for coronary heart disease. The researchers found that $80 \%$ of the husbands with wives that favored the program had good or excellent compliance with participation. While only $40 \%$ of the husbands had the same participation rating if the wives had a neutral or negative view of the program.

Prescribing lifestyle activities is another method of fitting exercise into a busy routine. Andersen et al. (1999) suggests that the use of lifestyle exercise suggestion is attractive to patients because they believe that it is something within their ability to initiate. Mentioned earlier in this paper, this study compared health outcomes in a group of obese women in a program of either lifestyle activity and diet, or structured aerobic activity and diet. They found that the lifestyle activity group had maintained their weight loss better at the one-year follow-up. The researchers believe that lifestyle activities may 
serve as a gateway into more traditional exercise activities through the increase in confidence for exercise generated by the lifestyle activities. Because these activities can be administered in short bouts throughout the day, they may also be easier to fit into a busy schedule, and need no specialized equipment.

Suggestions by therapists to achieve patient compliance included written instructions. In tests of recall of information, studies by Ley et al. (1972) have shown that after five minutes, patients forget about half the doctor's instructions, and that a written and oral combination, emphasizing the necessary information, results in the highest retention of information by the patient.

One of the unique comments made by a therapist was to "threaten" the patient. Although this may at first appear somewhat severe, often patients engage in behaviors that put their health and safety at risk. In this scenario, the "threat" could be merely a suggestion of what might occur if the patient persists in the current course of action. There is documentation by Kirscht and Haefner (1973) of this "fear-arousal" technique having a positive influence on patient compliance for medical treatment. Other research (Leventhal, 1971) finds that fear appeals are more likely to affect compliance when used initially to affect patient compliance, and are accompanied by specific recommendations that will act quickly and are easy to implement.

The seriousness of the word threat should not be totally ignored. Coy (1989) makes a case for autonomy-based informed consent in her article on ethical implications for patient noncompliance. Manipulating and coercing patients into doing what is "good for them" is not justifiable, and unless the word "threaten" was really meant to imply information of possible outcomes, then to threaten a patient would be unethical. Coy also 
suggests that therapists be aware of the impact that their behavior and form of communication can have on a patient.

The suggestion of paying the patients to enhance compliance was mentioned by one respondent. Studies in the literature suggest that this is actually an effective method. Making rewards dependent upon eliciting appropriate behaviors, or contingency contracting, has been studied for its effectiveness. Haynes et al. (1976) contracted thirtyeight steel workers with a verbal agreement to record their blood pressure and medication taking activity. Subjects were rewarded for their compliance by credit towards the purchase of a blood-pressure cuff and stethoscope. Results indicated $70 \%$ of the subjects showed increased compliance and decreased blood pressure. Steckel and Swain (1977) randomly assigned hypertensive outpatients to either a control group of a counseling program or an experimental group of counseling program plus contingency contract. The experimental group was reinforced with tangible rewards, such as lottery tickets, books, and money. The study found significant reduction in blood pressure and weight under the control conditions.

Burke refers to a study by Oldridge and Jones (1983) of self-management techniques for adherence in a cardiac rehabilitation program. Of all the techniques studied, only that of signing a contract for attendance made a difference in attendance practices. The attendance rate was $65 \%$ for those who signed, and $20 \%$ for those who did not sign the agreement. The researchers also found that persuasive communication combined with educational counseling of both the patient and the spouse generated an increase of $12 \%$ in attendance levels. 
Dunbar and Stunkard (1979) found the following advantages to creating patientprovider contracts: (1) clarification of behavioral expectations through a written outline; (2) patient involvement in the decision making process; (3) formal commitment to the accepted regimen; (4) reinforcements create incentives. Although establishing reinforcements in a clinical physical therapy setting may be impractical, the advice to the patient to set their own reward system to increase goal-oriented behavior could easily be dispensed.

The physical therapist as a model was also a suggestion by the therapists. Research in the literature by Harsha et al. (1996) demonstrated a link between physician characteristics and patient willingness to comply with exercise recommendations. Associations for greater influence to exercise existed between patients with higher education levels and characteristics of the physician including appropriate weight maintenance and non-smoking. For patients who regularly exercise, there was a positive influence in their exercise adherence due to the physician characteristics of appropriate weight and personal exercise regimen.

\section{Limitations of Study}

1. It involved a sample of convenience, and not a random sample of physical therapists. All the therapists in the study were members of the American Physical Therapy Association attending a Combined Sections meeting. These therapists may represent a more informed segment of the population of physical therapists, and therefore may be more aware of issues involved in patient compliance. It 
would be interesting to compare these results to a random sample of registered physical therapists nationwide.

2. There is the issue of category order effect, when the order in which answer choices are listed can affect how people respond. On mail surveys, people tend to pick the first answer most often, while on a telephone or face-to-face interview, they tend to pick the last (Salant and Dillman, 1994).

3. Question eight only included lifestyle changes made by therapists in the last three years. Including changes made more than three years prior may change the value of association between question seven and eight. Also, the behavioral changes included diet and smoking cessation in the belief that behavioral changes had similar sources (Prochaska and DiClemente, 1983). This may have also affected the outcome of the question.

\section{Suggestions for further research}

Further research into the practical application of methods to enhance patient compliance is needed. Provisions for child care and transportation to facilities, community access at facilities, and social support are methods to increase compliance. Pilot studies could be established to reveal effective ways to distribute community resources to provide these services.

Physical therapists need to conduct further research into factors affecting patient compliance specific to the field of physical therapy. Cardiac rehabilitation programs have low rates of compliance, and information gained from research in patient compliance would save lives and medical costs. 


\section{Summary}

The last several years have been a time of reduced services for physical therapy, and in order to continue to justify physical therapy service, increases in patient outcomes must be documented. Patient compliance with home exercise programs can help increase the efficacy of physical therapy treatment.

Numerous theories have been proposed as mechanisms that induce change (Bandura, 1977, Prochaska and DiClemente, 1983, Marlatt, 1988) in behavior. By utilizing some of these behavioral concepts, clinicians may have the ability to realize more benefits from their direct contact with patients. Expanding the concept of exercise from a focus on traditional exercises to include lifestyle activities may be a more effective method to induce lasting behavioral changes. The method of short bouts of activity (10 minutes) can fulfill American College of Sports Medicine recommendations and be readily adapted to lifestyle activities.

Attempting to reduce barriers to exercise can help the physical therapist to achieve patient compliance. Some of the factors associated with long-term compliance with exercise programs include low probability of injury, group participation, emphasis on variety and fun, use of personal goals and contracts, support networks, and positive feedback (Franklin, 1988).

This study found an association between therapists suggesting lifestyle activities to their patients and personally engaging in a lifestyle change for health reasons. The study by Walsh et al. (1999) found that physicians who felt they were successful in changing behavior were more likely to ask about and counsel about exercise. Perhaps the 
process of personal change increases the self-efficacy for perceived ability to induce change.

A study by Harsha et al. (1996) revealed that for patients whom regularly exercise, there was a positive influence in their exercise adherence due to the physician characteristics of appropriate weight and personal exercise regimen. A replication of this study using physical therapist, the providers whom usually prescribe exercise to patients would be informative.

Physical therapist should consider behavioral modification techniques that have proven effective in inducing change. These techniques can be garnered from diet, smoking cessation, and other behavioral change programs, and utilized in the physical therapy field. Therapists work to maximize patient benefits in a limited amount of time, but if these benefits end when therapy ceases, no permanent change evolves unless a behavioral change is induced. This is especially important in geriatric rehabilitation, when declines in functional ability can have a large impact on quality of life for the patients and their spouses.

Implementation of methods to increase patient compliance may increase longterm adherence to fitness programs. Stetson et al. (1995) conducted a study of cardiac rehabilitation patients adhering to a structured exercise program, to determine the strategies utilized by the thirty-six participants to remain in the exercise program. The majority of respondents used motivational self-talk related to goals to continue in their exercise routine. Other strategies utilized include cognitive distraction, and social distraction and interaction.

After reviewing the literature on patient compliance and the suggestions offered 
by physical therapists, I am offering ten suggestions to summarize the information from this study. These suggestions are not rank-ordered:

- Positive feedback. Several studies demonstrated the usefulness of this technique (Martin et al., 1984; Franklin, 1988; Sluijs and Knibbe, 1991; Sluijs et al., 1993; Crook et al., 1998). In this study $90.4 \%$ of the therapists found that positive feedback enhanced their patient compliance.

- Fit exercises into schedule. The least intrusive the behavioral change, the better the rate of compliance (Duncbar-Jacob et al., 1991). Time constraints are also a commonly listed barrier (Johnson et al. 1990;Godin et al., 1991; Bull et al., 1995; Andersen 1999; Dunn et al., 1999; Harnack et al., 1999). Lifestyle activity suggestions can act to save time and can be less intrusive methods.

- Consider trouble shooting for problems with the patients. Ask them which two factors are likely to increase their exercise rates, and which will decrease it. This way both the patient and therapist can consider how to maximize their efforts.

- Make a contract with the patient. For those patients who need long-term changes, try a written contract. Material in writing tends to increase the patient compliance (Oldridge and Jones, 1983, Franklin, 1988). This enhances personal responsibility for exercise.

- Follow up on patients. Health care practices have resulted in a decrease in patient-provider interactions. A phone call or letter has been shown to increase compliance (McCauley, 1993). 
- Enlist the help of family, friends, and caretakers. Encouragement by those involved with the patient has been demonstrated to increase patient compliance (Heinzelmann and Bagley, 1970; Oakes et al., 1970; Lieberman et al., 1998; Nies et al., 1998).

- Give the patients options (Dunbar and Strunkard, 1979). Ask the patients what exercises they think they will actually perform, and explain thoroughly and in an understandable method the advantages of various exercises.

- Let the patients tell you why they are doing the exercises and show how they are done. If they know why they are doing what they are doing, and they are confident they are doing it correctly, it will increase the probability of their actually performing the exercises.

- Make exercises realistic. This will also help the patients understand the exercise and elicit their cooperation (Gage and Polatajko, 1994).

- Consider diversion tactics to make exercise more enjoyable, such as group exercise, television and radio, or thinking "pleasant thoughts," or things that you do personally to help with exercise behavior. Although it might seem that these things are obvious, the patients may not be considering them, and there is evidence that diversions increase exercise compliance. 


\section{REFERENCES}

American College of Sports Medicine (1998). American College of Sports Medicine Position Stand. The recommended quantity and quality of exercise for developing and maintaining cardiorespiratory and muscular fitness, and flexibility in healthy adults. Medical Science and Sports Exercise, 30(6), 975991.

American College of Sports Medicine (1998b). American College of Sports Medicine Position Stand. Exercise and Activity for older adults. Medical Science and Sports Exercise, 30(6), 992-1008.

American Heart Association (1995). American Heart Association: Heart and Stroke Facts: 1996 Statistical Supplement. Dallas, TX: author.

Andersen, R. E. (1999). Exercise, an active lifestyle, and obesity. The Physician and Sportsmedicine, 27, 41-48.

Andersen, R. E., Wadden, T. A., Bartlett S. J., Zemel B., Verde T. J., \& Franckowiak, S. C. (1999). Effects of lifestyle versus structured aerobic exercise in obese women. Journal of the American Medical Association, 281(4), 335-340.

Bandura, A. (1977). Self-efficacy: Toward a unifying theory of behavioral change. Psychological review, 84(2),191-215.

Becker, M. H., \& Maiman, L. A. (1975). Sociobehavioral determinants of compliance with health and medical care recommendations. In: Becker, M. H., \& Maiman, L. A. (1980). Strategies for enhancing patient compliance. Journal of Community Health, 6(2),113-135.

Becker, M. H., \& Maiman, L. A. (1980). Strategies for enhancing patient compliance. Journal of Community Health, 6(2),113-135.

Blackwell, B. (1992). Compliance. Psychotherapy and Psychosomatics, $58,161-169$

Bock, B. C., Albrecht, A. E., Traficante, R.M., Clark, M. M., Pinto, B. M., Tikeemeier, P., \& Marcus, B. H. (1997). Predictors of exercise adherence following participation in a cardiac rehabilitation program. International Journal of Behavioral Medicine, 4(1), 60-75.

Booth, M.L., Bauman, A., Owen, N., \& Gore, C. J. (1997). Physical activity preferences, preferred sources of assistance, and perceived barriers to increased activity among physically inactive Australians. Preventative Medicine, 26(1), 131-137. 
Bull, F. C., Schipper, E. C., Jamrozik, K., \& Blanksby, B., A. (1995). Beliefs and behavior of general practitioners regarding promotion of physical activity. Australian Journal of Public Health, 19(3), 300-304.

Burke, L. E., Dunbar-Jacob, J. M., \& Hill, M. N. (1997). Compliance with cardiovascular disease prevention strategies: A review of the research. Annals of Behavioral Medicine, 19(3), 239-263.

Chen, C. Y., Neufeld, P. S., Feely, C. A., \& Skinner, C.S. (1999). Factors influencing compliance with home exercise programs with upper extremity impairment. The American Journal of Occupational Therapy, 53(2), 171-180.

Clark, D. O. (1999). Physical activity and its correlates among primary care patients aged 55 years and older. Journal of Gerontology: Psychological Sciences, 54(1), 41-48.

Clopton N. (1992). Patient compliance. Clinical Management, 12(1), 5965.

Conn, V.S. (1998). Older adults and exercise: Path analysis of selfefficacy. Nursing Research, 47(3), 180-189.

Cousins, S. O. (1996). Exercise cognition among elderly women. Journal of Applied Sport Psychology, 8, 131-145.

Coy, J. A. (1989). Autonomy-based informed consent: Ethical implications for patient noncompliance. Physical Therapy, 69(10), 826-833.

Crook, P., Rose, M., Salmon, P., Stott, R, Peters, S., \& Stanley, I. (1998). Adherence to group exercise: Physiotherapist-led experimental programmes. Physiotherapy, 84(8), 366-371.

Davis, M. S. Variations in patients' compliance with doctors' advice: An empirical analysis of patterns of communication. (1969) In: Becker, M. H., \& Maiman, L. A. (1980). Strategies for enhancing patient compliance. Journal of Community Health, 6(2),113-135.

Desmond A. W., Conrad, K. M., Montgomery, A., \& Simon, K. A. (1993) Factors associated with a male workers' engagement in physical activity: White collar versus blue collar workers. American Association of Occupational Health Nursing, 41(2), 73-83.

Dishman, R. K. (1988). Exercise Adherence: Its Impact on Public Health. (p. 1-9) Champaign, Ill: Human Kinetics Publishers Inc. 
Dishman, R. K., Sallis, J. F., \& Orenstein, D. R. (1985). The determinants of physical activity and exercise. In: Dunlap, J., \& Barry, H. C. (1999). Overcoming exercise barriers in older adults. The Physician and Sportsmedicine, 27(11), 69-75.

Dunbar, J. M., \& Strunkard, A. J. (1979). Adherence to diet and drug regimen. In: Becker, M. H., \& Maiman, L. A. (1980). Strategies for enhancing patient compliance. Journal of Community Health, 6(2),113-135.

Dunlap, J., \& Barry, H. C. (1999). Overcoming exercise barriers in older adults. The Physician and Sportsmedicine, 27(11), 69-75.

Duncbar-Jacob, J., Dwyer, K., \& Dunning, E. J. (1991). Compliance with antihypertensive regimen: A review of the literature. In: Burke, L. E., DunbarJacob, J.M., \& Hill, M. N. (1997). Compliance with cardiovascular disease prevention strategies: A review of the research. Annals of Behavioral Medicine, 19(3), 239-263.

Dunn, A. L., Marcus, B. H., Kampert, J. B., Garcia, M. E., Kohl, H. W., \& Blair, S. N. (1999). Comparison of lifestyle and structured interventions to increased physical activity and cardiorespiratory fitness. Journal of the American Medical Association, 281(4), 327-334.

Erikssen, G., Liestol, K., Bjornholt, J., Thaulow, E., Sandvik, L., \& Erikssen, J. (1998). Changes in physical fitness and changes in mortality. Lancet, 352(9130), 759-762.

Eyler, A. A., Baker, E., Cromer, L., King, A. C., Brownson, R. C., \& Donatelle, R. J. (1998). Physical activity and minority women: a qualitative study. Health Education and Behavior, 25(5), 640-652.

Ewart, C. K., Taylor, B., Reese, L. B., \& DeBusk, R. F. (1983). Effects of early postmyocardial infarction exercise testing on self-perception and subsequent physical activity. The American Journal of Cardiology, 51, 1076-1080.

Franklin, B. (1988). Program factors that influence exercise adherence: Practical adherence skills for the clinical staff. In: Dishman, R. K. (Ed.), Exercise Adherence: Its Impact on Public Health. (p. 237-258) Champaign, Ill: Human Kinetics Publishers Inc.

Friday, G. H. (1999). Antihypertensive medication compliance in African-American stroke patients: Behavioral epidemiology and interventions. Neuroepidemiology, 18(5), 223-230. 
Gage, M., \& Polatajko H. (1994). Enhancing occupational performance through an understanding of perceived self-efficacy. The American Journal of Occupational Therapy, 48(5), 452-461.

Gecht, M. R., Connel, K. J., Sinacore, J. M., \& Prochaska, T. R. (1996). A survey of exercise beliefs and habits among people with arthritis. Arthritis Care Research, 9(2), 82-88.

Gillett, P. A. (1988). Self reported factors influencing exercise adherence in overweight women. Nursing Research, 37(1), 25-29.

Godin, G., Valois, P., Jobin, J., \& Ross, A. (1991). Prediction of intention to exercise of individuals who have suffered from coronary heart disease. Journal of Clinical Psychology, 47(6), 762-72.

Harnack, L., Story, M., \& Rock B. H. (1999). Diet and physical activity patterns of Lakota Indian adults. Journal of American Dietetic Association, 99(7), 829-835.

Harsha, D. M., Saywell, R. M., Thygerson, S., \& Panozzo, J. (1996). Physician factors affecting patient willingness to comply with exercise recommendations. Clinical Journal of Sports Medicine, (6), 112-118.

Haynes, R. B., Sackett, D. L., \& Gibson, E. S. Improvement of medication compliance in uncontrolled hypertension. Lancet, 1, 1265-1268.

Heinzelmann, F., \& Bagley, R. W. (1970). Response to a physical activity programs and their effects on health behavior. In: Becker, M. H., \& Maiman, L. A. (1980). Strategies for enhancing patient compliance. Journal of Community Health, 6(2), 113-135.

Henry, K. D., Rosemond, C., \& Eckert L. B. (1998). Effects of the number of home exercises on compliance and performance in adults over 65 years of age. Physical Therapy, 78(3), 270-277.

Horne T. E. (1994). Predictors of physical activity intentions and behavior for rural homemakers. Canadian Journal of Public Health, 85(2), 132-135. 1839.

Ice, R. Long-term compliance. (1985). Physical Therapy,65(12), 1832

Jakicic, J. M., Wing, R. R., Butler, B. A., \& Robertson, R. J. (1995). Prescribing exercise in short bouts versus one continuous bout: Effects on adherence, cardiorespiratory fitness, and weight loss in overweight women. International Journal of Obesity, 19, 893-901. 
Jensen, G. M., \& Lorish, C. (1994). Promoting patient cooperation with exercise programs: linking research, theory, and practice. Arthritis Care Research, 7(4), 81-189.

Johnson, C. A., Corrigan, S. A., Dubbert, P. M., \& Gramling, S. E. (1990) Perceived barriers to exercise and weight control practices in community women. Women's Health, 16(3), 177-191.

Johnson, N. A., \& Heller, R. F. (1998). Prediction of patient nonadherence with home-based exercise for cardiac rehabilitation: The role of perceived barriers and perceived benefits. Preventative Medicine, 27(1), 56-64.

Jones, D. A., Ainsworth, B. E., Croft, J. B., Macera, C. A., Lloyd, E. E., \& Yusuf, H. R. (1998). Moderate leisure-time activity: Who is meeting the public health recommendations? A national cross-sectional study. Archives of Family Medicine, 7(3), 285-289.

Jones, M., \& Nies, M. A. (1996). The relationship of perceived benefits of and barriers to reported exercise in older African American women. Public health Nursing, 13(2), 151-158.

Kadzin, A. E. (1973). Covert modeling and the reduction of avoidance behavior. Journal of Abnormal Psychology, 81, 87-95. In: Bandura, A. (1977). Self-efficacy: Toward a unifying theory of behavioral change. Psychological review, 84(2), 191-215.

Kavanaugh, T., Shephard, R. J., \& Pandit, V. (1974). Marathon running after myocardial infarction. Journal of the American Medical Association, 229(12), 1602-1605.

Kemp, B. J. (1988). Motivation, rehabilitation, and aging: A conceptual model. Topics in Geriatric Rehabilitation, 3(3), 41-51.

Kempen, G. I. J. M., Van Sonderen, E., \& Ormel, J. (1999). The impact of psychological attributes on changes in disability among low-functioning older persons. Journal of Gerontology: Psychological Sciences, 54B(1), 23-29.

Kirscht, H., \& Haefner, D. P. (1973). Effects of repeated threatening health communications. In: Becker, M. H., \& Maiman, L. A. (1980). Strategies for enhancing patient compliance. Journal of Community Health, 6(2), 113-135.

Knapp, D. N. ( 1985). Behavioral management techniques and exercise promotion. In: Dishman RK, (Ed.) Exercise Adherence: Its Impact on Public Health (p. 203-235). Champaign, Ill: Human Kinetics Publishers Inc. 
Leventhal, H. (1971). Fear appeals and persuasion: The differentiation of a motivational construct. In: Becker, M. H., \& Maiman, L. A. (1980). Strategies for enhancing patient compliance. Journal of Community Health, 6(2),113-135.

Ley P. (1972). Primacy, rated importance, and the recall of medical statements. In: Becker, M. H., \& Maiman, L. A. (1980). Strategies for enhancing patient compliance. Journal of Community Health, 6(2), 113-135.

Lieberman, L., Meana, M., \& Stewart, D. (1998). Cardiac rehabilitation: Gender differences in factors influencing participation. Journal of Women's Health, 7(6), 717-723.

Marlatt, G. A. (1988). Relapse prevention: Theoretical rationale and overview of the model. In: Dishman RK, (Ed.) Exercise Adherence: Its Impact on Public Health (p. 186-202). Champaign, Ill: Human Kinetics Publishers Inc.

Martin, J. E., \& Tubbert, P. M. (1984). Behavioral management strategies for improving health and fitness. In: Ice, R. Long-term compliance. (1985). Physical Therapy, 65(12), 1832-1839.

Martin, J. E., Dubbbert, P. M., Katell, A. D., Thompson, J. K., Raczynski, J. R., Lake M., Smith, P. O., Webster, J. S., Sikora, T., \& Cohen, R. E. (1984). Behavioral control of exercise in sedentary adults: Studies 1 through 6. Journal of Consulting and Clinical Psychology, 52, 795-811.

Mazullo, J., Lasagna, L., \& Grinar, P. Variations in interpretations in prescription instructions. (1974). Journal of the American Medical Association, 227, 929-931.

McAuley, E., Lox, C., \& Duncan, T. E. (1993). Long-term maintenance of exercise, self-efficacy, and physiological change in older adults. Journal of Gerontology, Psychological Sciences, 48(4), 218-224.

McKenna, J., Naylor, P. J., \& McDowell, N. (1998). Barriers to physical activity promotion by general practitioners and practice nurses. British Journal of Sports Medicine, 32(3), 242-247.

Moffett, J. A. K., \& Rchardson, P. H. (1997). The influence of the physiotherapsit-patient relationship on pain and disability. Physiotherapy Theory and Practice, 13(1), 89-96.

Muto, T., Saito, T., \& Sakurai, H. (1996). Factors associated with male workers' participation in regular physical activity. Industrial Health, 34(4), 307321. 
Naslund, G. K., Fredrikson, M., Hellenius, M. L., \& de Faire, U. (1996) Determinants of compliance in men enrolled in a diet and exercise intervention trial: a randomized, controlled study. Patient Education and Counseling, 29(3), 247-256.

Nies, M. A., Vollman, M., \& Cook, T. (1999). African American women's experiences with physical activity in their daily lives. Public Health Nursing, 16(1), 23-31.

Nies, M. A., Vollman, M., \& Cook, T. (1998). Facilitators, barriers, and strategies for exercise in European American women in the community. Public Health Nursing, 15(4), 263-272.

Oakes, T. W., Ward, J. R., \& Gray, R. Family expectations and arthritis patient compliance to a hand-resting splint regimen (1970). In: Becker MH, Maiman LA. (1980). Strategies for enhancing patient compliance. Journal of Community Health, 6(2), 113-135.

Oldridge, N. B. (1998). Compliance with exercise in cardiac rehabilitation. In: Dishman RK, (Ed) Exercise Adherence: Its Impact on Public Health (p. 283-304). Champaign, Ill: Human Kinetics Publishers Inc.

Oldridge, N. B., \& Jones, N. L. (1983). Improving patient compliance in cardiac exercise rehabilitation: Effects of written agreement and self-monitoring. In: Burke, L. E., Dunbar-Jacob, J. M., \& Hill, M. N. (1997). Compliance with cardiovascular disease prevention strategies: A review of the research. Annals of Behavioral Medicine, 19(3), 239-263.

Perri, M. G., Martin, A. D., Leermakers, E. A., Sears, S. F., \& Notelovitz, M. (1997). Effects of group-versus home- based exercise in the treatment of obesity. Journal of Consulting Clinical Psychology, 65(2), 278-285.

Prochaska, J. O., \& DiClemente, C. C. (1983). Stages and process of selfchange of smoking: Toward an integrative model of change. Journal of Consulting and Clinical Psychology, 51(3), 390-395.

Resnick, B. (1996). Motivation in geriatric rehabilitation. Journal of Nursing Scholarship, 28(1), 41-45.

Rhodes, R. E., Martin, A. D., Taunton, J. E., Rhodes, E. C., Donnely, M., \& Elliot, J. (1999). Factors associated with exercise adherence among older adults: An individual perspective. Sports Medicine, 28(6), 397-411. 
Salant, P., \& Dillman, D. (1994). How to Conduct your Own Survey. New York, NY: John Wiley \& Sons, Inc.

Scharff, D. P., Holmes, S., Kreuter, M., \& Brennen, L. (1999). Factors associated with physical activity in women across the lifespan: Implications for program development. Women's Health, 29(2), 115-134.

Simkin, L. R., \& Gross, A. M. (1994). Assessment of coping with high risk situations for exercise relapse among healthy women. Health Psychology, 13(3), 274-277.

Sluijs, E. M., \& Knibbe, J. (1991). Patient compliance with exercise: Different theoretical approaches to short-term and long-term compliance. Patient Education and Counseling, 17, 191-204.

Sluijs, E. M., Kok, G. J., \& Van der Zee, J. (1993). Correlates of exercise compliance in physical therapy. Physical Therapy, 73(11), 41-52.

Sluijs, E, M., \& Kuijper, E. B. (1990). Problems therapist encounter in educating patients. In: Sluijs, E. M., Kok, G. J., \& Van der Zee, J. (1993). Correlates of exercise compliance in physical therapy. Physical Therapy, 73(11), 41-52.

Sorenson, M. (1997). Maintenance of exercise behavior for individuals at risk for cardiovascular disease. Perceptual and Motor Skills, 85(3), 867-880.

Stenstrom, C. H., Arge, B., \& Sunbom, A. Home exercise and compliance in inflammatory rheumatic diseases: A prospective clinical trial. Journal of Rheumatology, 24(3), 470-476.

Sternfeld, B., Ainsworth, B. E., \& Quesenberry, C. P. (1999). Physical activity patterns in a diverse population of women. Preventative Medicine, 28(3), 313-323

Stetson, B. A., Frommelt, S. J., Boutelle, K. N., \& Cole, J. Exerciserelated thoughts in cardiac exercise programs: A study of exercise-adherent cardiac rehabilitation patients. International Journal of Rehabilitation and Health, $1(2), 125-136$

Straka, R. J., Fish, J. T., Benson, S. R., Suh, J. T. (1996). Magnitude and nature of noncompliance with treatment using isosorbide dinitrate in patients with ischemic heart disease. Journal of Clinical Pharmacology, 36(7), 587-594.

Taylor, C. B., Bandura, A., Ewart, C. K., Miller, N. H., \& DeBusk, R. F. (1985). Raising spouse's and patient's perceptions of his cardiac capabilities 
following a myocardial infarction. In: O'Leary A. Self-efficacy and Health. Behavioral Research Therapy, (4), 437-451.

Tran, Z. V., Weltman, A., \& Glass, G.V. (1983). The effects of exercise on blood lipids and lipoproteins: A meta-analysis of studies. Medicine and Science in Sports and Exercise, 15(5), 393-402.

Verhoef, M. J., \& Love, E. J. (1992). Women's exercise participation: The relevance of social roles compared to non-role related determinants. Canadian Journal of Public Health, 83(5), 367-370.

Walsh, J. M., Swangard, D. M., Davis, T., \& McPhee, S. J. (1999). Exercise counseling by primary care physicians in the era of managed care. American Journal of Preventative Medicine, 16(4), 307-313.

Wannamethee, S. G., Shaper, A. G., \& Walker, M. (1998). Changes in physical activity, mortality, and incidence of coronary heart disease in older men. Lancet, 351(9116), 1603-1608.

Wenger, N. K. (1997). Cardiac Rehabilitation: Implication of the AHCPR guideline. Hospital Medicine, 33(4), 31-38.

Williford, H. N., Barfield, B. R., Lazenby, R. B., \& Olson M. S. (1992). A survey of physicians' attitudes and practices related to exercise promotion. Preventative Medicine, 21(5), 630-636. 
Dear APTA member:

I am a graduate student in physical therapy at Florida International University, finishing my Master's thesis. The questionnaire I would like you to complete will be used in my research on patient compliance issues in physical therapy. Respondents to the questionnaire will remain anonymous. If you would like information about the results of this research, please submit your e-mail or written address on this form and I will send the results to you. Thank you for your time and cooperation in completing this questionnaire. I hope the results will be informative and useful

Sincerely,

Victoria R. Benea, PT

Email address:

Mailing address: 
Data:

$\begin{array}{ll}\text { 1) Years of practice as a physical therapist: } & \text { 2) What state do you live in? }\end{array}$

3) How old are you?

Questionnaire:

1) Approximately what percentage of your patients receive home exercise programs?

2) Approximately what percentage of your patients receive suggestions of lifestyle activities as part of their exercise programs?

3) Rank order the following reasons patients give for not complying with a home exercise program: _ inconvenient _ not enough time __ no motivation __ too strenuous _ cannot perform exercises __ pain _ _ other (list)

4) I have found that increasing positive feedback has increased compliance with exercise programs in my patient population.

Strongly Agree Somewhat Agree Undecided Somewhat Disagree Strongly Disagree

5) I ask all my patients for feedback on how they feel the exercises I prescribe have been effective.

Strongly Agree Somewhat Agree Undecided Somewhat Disagree Strongly Disagree

6) I often mention ways to make "boring" exercises more amusing to patients by suggesting methods such as watching television, listening to the radio or having a buddy while exercising.

Strongly Agree Somewhat Agree Undecided Somewhat Disagree Strongly Disagree

7) I engage in an exercise routine lasting at least 20 minutes for 3 times a week or more.

Strongly Agree Somewhat Agree Undecided Somewhat Disagree Strongly Disagree

8) I have made a lifestyle change, such as a change in eating habits, smoking cessation, or starting an exercise program in the last three years.

Strongly Agree Somewhat Agree Undecided Somewhat Disagree Strongly Disagree

What is the most important advice you would give a physical therapy student regarding the best way to achieve patient compliance? 